\title{
Winogradsky-type columns as an insight into mineral neoformation and metal mobility in acidic pit lakes
}

\author{
A. ILIN $^{1 *}$, I. YUSTA $^{1}$, J. SÁNCHEZ-ESPAÑA ${ }^{2}$
}

${ }^{1}$ University of the Basque Country (UPV/EHU), Apdo. 644, Bilbao, Spain (*correspondence: andrey.ilin@ehu.eus, i.yusta@ehu.eus)

${ }^{2}$ Spanish Geological Survey (IGME), Calera 1, 28760, Tres Cantos, Madrid, Spain (j.sanchez@igme.es)

Abundant mineral neoformation is typically observed in Acidic Pit Lakes (APL) water column and bottom sediments. A wide $\mathrm{pH}$ range (1.9-4.5), high ionic strength, high metallic contents (e.g. Al, Fe, Mg, Mn, Cu, Zn, Ni, Cd, As, U), strong statification (meromixis) and sharp vertical gradients allow to investigate the dynamics of a variety of oxic and anoxic, highly acidic systems. Research methods include on-site boatbased physico-chemical profiling followed by water sampling at different depths, further filtration to separate pelagic mineral particles and water for chemical analysis [1], in-lake deployment of sediment traps and mineral precipitation traps [2], chemical laboratory assays and geochemical modelling. These tecnhiques have limitations, mainly because microorganism-metal-mineral interactions are usually very slow in nature, thus obscuring neoformed phases among detritial ones, and also because of the high depths (more than 40-100 m) at which these interactions take place.

Recently, the use of Winogradsky-type incubation columns has proven to be highly useful model systems to investigate geomicrobial interactions [3]. Filling it with acidic mine water and sediment from a selected depth allows to simulate in-lake conditions and user-friendly monitorization of geochemical parameters (e.g. $\mathrm{pH}$ evolution, ORP, nutrients) and mineral neoformation and diagenesis. New mineral phases include $\mathrm{Fe}-\mathrm{Al}$ (oxy)hydroxysulfates, $\mathrm{Fe}$ oxyhydroxides and less studied $\mathrm{Fe}-\mathrm{Cu}-\mathrm{Zn}$ sulfides. The addition of glycerol to selected columns provoked the exponential growth of sulfate-reducing microorganisms and firm raise of $\mathrm{pH}$ inducing a much higher rate of sulfide formation. The evolution in untreated and cooled-stored (4 ${ }^{\circ} \mathrm{C}$ ) columns was rather limited. In this on-going experiment we expect to investigate mineral cristallinity and metal mobility during early diagenetic processes and microbial community evolution with possible environmental implications.

[1] Sánchez-España et al. (2020) MINE WATER ENVIRON, 1-21. [2] Yusta et al. (2011) Macla 15, 201-202. [3] DiezErcilla et al. (2019) J SOIL SEDIMENT 19, 1527-1542. 